\title{
Optimization of Travel in Bus Rapid Transit-Based Multimodal Corridors
}

\author{
Shahriar A. Zargari, Iran University of Science and Technology \\ Ata M. Khan, Carleton University
}

\begin{abstract}
Frequently, urban transportation infrastructure and services are operated in a suboptimal manner with respect to key policy objectives such as enhancing mobility, avoiding severe congestion, improving public transit ridership, reducing fuel consumption, and emissions. To overcome this problem, a hybrid simulation-optimization methodology was developed for identification of values of demand management variables that result in the most favorable travel condition in a multimodal corridor regarding a policy objective. This methodology was applied to a bus rapid transitbased major travel corridor in Ottawa (Canada). The travel simulation part of the model is implemented within the EMME/2 modeling framework, supported by a transitway simulation technique. The optimization part of the methodology is based on direct search method that identifies the optimal values of key demand management variables for policy responsiveness. Optimization results are presented for bus modal split, in-vehicle travel time, fuel consumption, and greenhouse gas emission.
\end{abstract}

\section{Introduction}

Improved public transit ridership is essential for avoiding severe traffic congestion and reducing fuel consumption and emissions. In urban transportation corridors, public transit services compete with the private automobile to attract and retain 
choice riders. Building a rapid transit system (e.g. a bus-based system) and providing lanes on streets for the exclusive use of buses are a step in this direction. However, additional actions, such as travel demand management measures, can be taken to enhance the policy responsiveness of the corridor.

Potentially, bus fare, parking charges, and tolls on freeways can be used to divert a significant proportion of automobile users to public transit, therefore avoiding severe traffic congestion and reducing fuel consumption and emissions. While transit fare and parking charges are traditional measures used in demand modeling, charging tolls on urban freeways is an idea that is gaining momentum in North America (Smart Urban Transport 2002). In planning urban transit services, these three demand management or control variables (i.e., transit fare, parking charge, and toll) can be used to alter modal travel so as to attain policy objectives. From a methodological perspective, the challenge is to find the values of these variables that will, for example, minimize in-vehicle travel time. Likewise, it would be of interest to reduce fuel consumption and greenhouse gas (GHG) emissions.

In the current practice, sensitivity analyses are carried out by making changes to input variables and checking the result. This can be time consuming and there is no guarantee that the optimal value of the objective function can be found by trial-and-error method.

This article describes a methodology that identifies the values of demand management variables for optimizing travel in order to achieve a specified policy objective (e.g., minimization of in-vehicle travel time). The methodology is illustrated for a major corridor in the city of Ottawa (Canada) that features a bus rapid transit as well as a freeway and arterials roads.

\section{Methodological Framework}

A hybrid simulation-optimization methodology was developed that enables the optimization of travel in a multimodal corridor according to well-defined objectives such as reducing in-vehicle time, improving energy efficiency, reducing GHG emissions, improving air quality, etc. (Figure 1). The travel simulation model was structured by using the EMME/2 software (INRO 1999) and was calibrated for use in the Ottawa (Canada) case study. Government agencies contributed data and other information regarding the transportation network, technology factors, and origin-destination travel. 


\section{Figure 1. Simulation-0ptimization Hybrid Method}

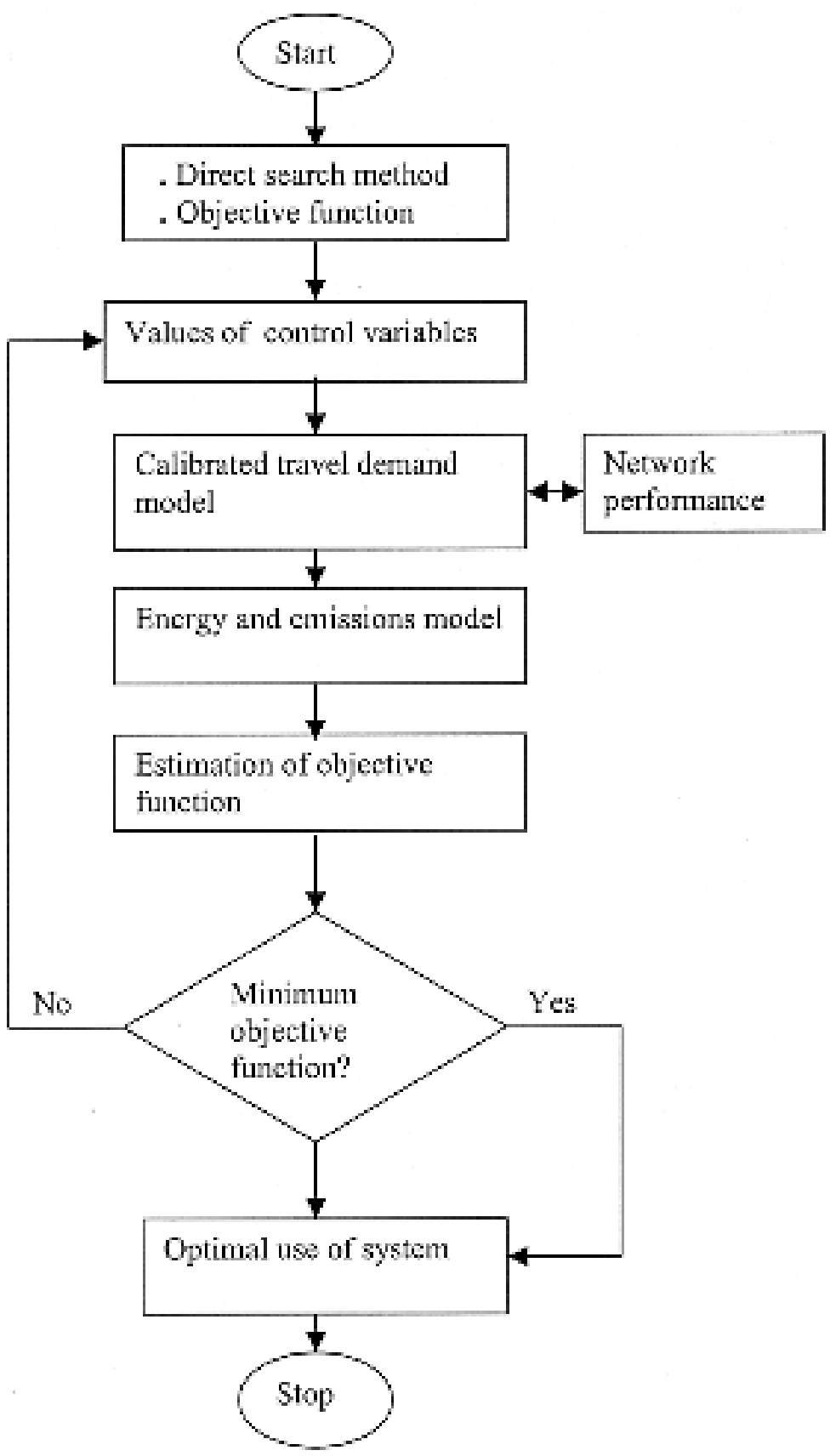


To supplement the capabilities of the EMME/2 software, the following methodologies were developed for use in this research study:

- Transitway simulation technique for estimating travel time and other service quality factors (Zargari and Khan 1998)

- Energy consumption and emission macro (Zargari and Khan 2003)

- An optimization model, based on direct search method, for the identification of the optimal values of key demand management variables

Details of the optimization method are presented in this article.

A sequence of steps is required to achieve the optimal travel condition in response to a specified policy objective:

1. The objective function is to be defined that is to be optimized (e.g., minimizing in-vehicle travel time per pass-km, minimizing fuel consumption per pass-km). Each objective function requires a separate application of the methodology.

2. A set of control variables are to be defined that can potentially alter modal travel demand (e.g., public transit fare, parking charge, highway toll, etc.).

3. A realistic range of values for the control variables is to be specified. For example, the planner may want to exclude such hypothetical cases as "free transit."

4. The travel demand model in the EMME/2 framework has to be calibrated and initialized.

5. The initial level of service factors (e.g., link level travel time/link average speed) in equilibrium condition have to be calculated by using EMME/2.

6. In a new equilibrium condition resulting from the use of specified values of control variables, corridor travel demand (i.e., person trips for each mode) and its effects (e.g., link travel time, fuel consumption, and emissions) are to be estimated.

7. The objective function is to be quantified on the basis of model outputs.

8. The best values for control variables (which are commonly known as demand management variables) are to be found by using the optimization method. This requires changing values of the control variables, estimating 
travel demand and corresponding volumes on links, and estimating impacts. Following the feedback process, the equilibrium condition is attained. The outputs form the basis of the new value of the objective function. This value is compared with its previously calculated value. The design of the optimization model will signal the user to change values of control variables in order to move in the direction of the optimal magnitude of the objective function.

9. The values of control variables that result in the optimal magnitude of the objection function (e.g., minimum in-vehicle travel time per pass-km) are recommended for implementation.

\section{Optimization Methodology}

For the minimization of an objective function, such as fuel consumption per pass$\mathrm{km}$, a method is needed to solve the optimization problem. The direct search method, a branch of numerical search techniques, is selected for this purpose (Radin 1998, Nicholson 1971). Functions used in travel forecasting, network performance assessment, and fuel and emission estimation are nonlinear and it is difficult to compute their gradients. This makes use of analytical methods (i.e., nonlinear programming) unfeasible. The direct search method is best suited for functions that do not have a well-defined form. Computing time is not an issue given the capabilities of present generation of computers and the fact that we are dealing with a limited number of control variables (i.e., parking fee, highway toll, and transit fare). Over the years, direct search methods were developed and used successfully, mostly in the telecommunications field.

The direct search method uses the process of systematically evaluating different choices for the control variables. Figure 2 presents the concept of the direct search method. According to its design, the analyst works directly with the objective function by examining values at a series of points, in accordance with a carefully directed search across the feasible region (Radin 1998, Nicholson 1971). 


\section{Figure 2. Direct Search Method}

Source: Adapted from Nicholson (1971).

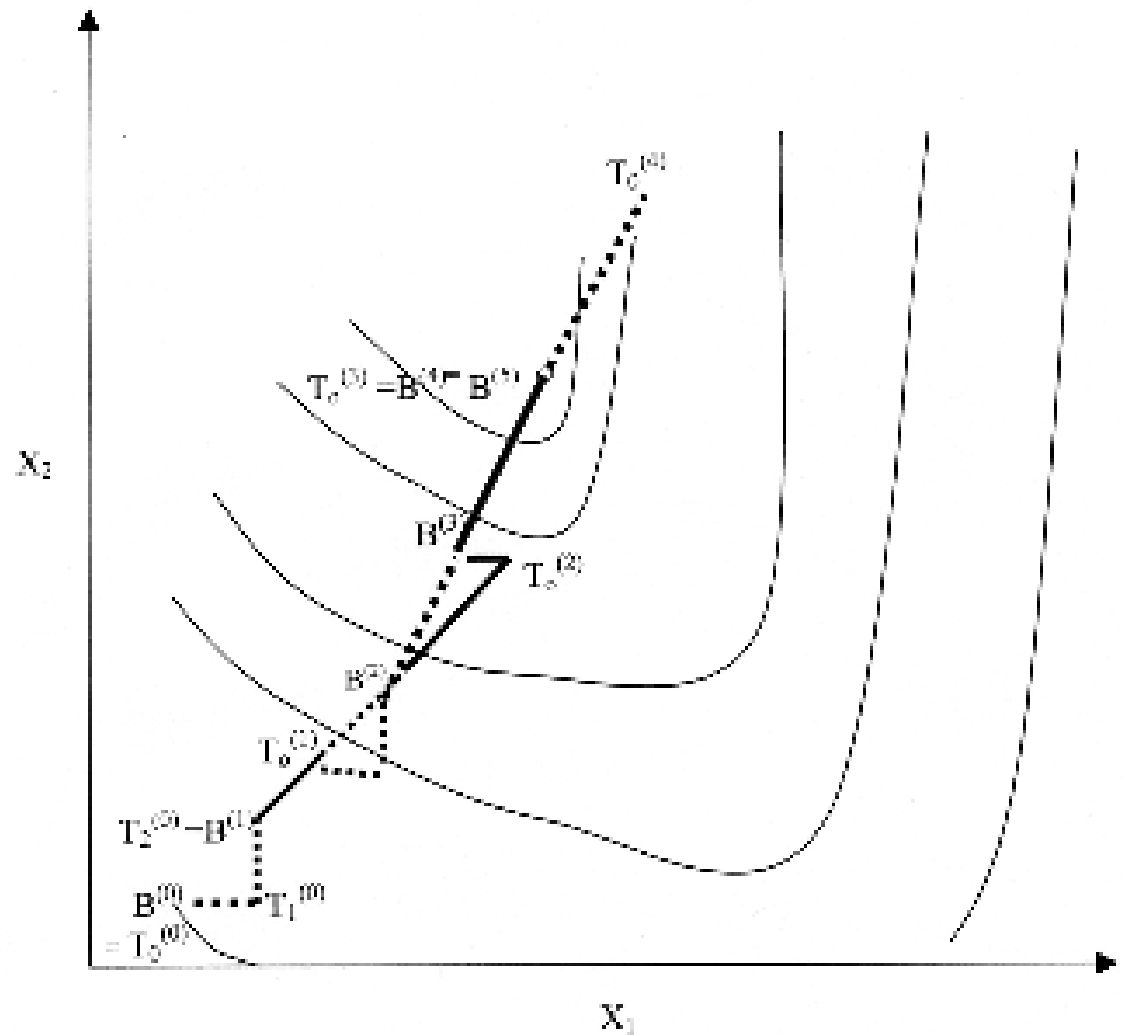

The intent is to minimize a function of $n$ variables $f(X)$. The search procedure can be described in terms of base points and temporary positions (Nicholson 1971). The starting point is defined by the initial (i.e., minimum) values of variables specified by the analyst. This is called the first base point, denoted by:

$$
\mathrm{X}=\mathrm{B}^{(0)}=\left(\mathrm{b}_{1}{ }^{(0)}, \mathrm{b}_{2}{ }^{(0)}, \ldots . \mathrm{b}_{\mathrm{n}}{ }^{(0)}\right)
$$

Where:
$\mathrm{B}^{(0)}$ is the first base point
$\mathrm{b}_{1}{ }^{(0)}, \mathrm{b}_{2}{ }^{(0)}, \ldots . \mathrm{b}_{\mathrm{n}}{ }^{(0)}$ are the initial values of variables 
The objective function is estimated at $\mathrm{B}^{(0)}$ and its value is noted as $\mathrm{f}\left(\mathrm{B}^{(0)}\right)$. Then a step length $\delta_{i}$ is defined for each variable $x_{i}$. This is expressed in the vector $\Delta_{i}$ whose ith component is $\delta$ iand all other components are set equal to the minimum values for each variable. The next step is to perturb or change the value of the variable according to step lengths $+\delta_{i}$ or $-\delta_{i}$ The change can be accepted if it leads to an improvement in the value of the objective function. Following the perturbation of each variable, the new base point $\mathrm{B}^{(1)}$ is reached. According to this method, local perturbations are studied first.

Following the perturbation of the variable $\mathrm{x}_{1}$ and by using the new base point $\left(\mathrm{B}^{(0)}\right.$ $\left.+\Delta_{1=} \mathrm{B}^{(1)}\right)$, the objective function is estimated at $\mathrm{B}^{(1)}$ and expressed as $\mathrm{f}\left(\mathrm{B}^{(1)}\right)$. If $\mathrm{f}\left(\mathrm{B}^{(1)}<\mathrm{f}\left(\mathrm{B}^{(0)}\right)\right.$, then the point $\mathrm{B}^{(1)}$ is called the temporary position and is designated by $\mathrm{T}_{1}{ }^{(0)}$. Otherwise, if $\mathrm{f}\left(\mathrm{B}^{(1)}>\right.$ or $=\mathrm{f}\left(\mathrm{B}^{(0)}\right)$, it should be estimated as $\mathrm{f}\left(\mathrm{B}^{(0)}\right.$ $\Delta_{1}$ ) (if applicable). If it is less than $\mathrm{f}\left(\mathrm{B}^{(0)}\right)$, this is the temporary position. If no improvement occurs, $\mathrm{B}^{(0)}$ is denoted as the temporary position. Therefore, we can find $\mathrm{T}_{1}{ }^{(0)}$ from one of the following three relations:

$$
\mathrm{T}_{1}^{(0)}=\mid \begin{aligned}
& \mathrm{B}^{(0)}+\Delta_{1}, \text { if } \mathrm{f}\left(\mathrm{B}^{(0)}+\Delta_{1}\right)<\mathrm{f}\left(\mathrm{B}^{(0)}\right) \\
& \mathrm{B}^{(0)}-\Delta_{1}, \text { if } \mathrm{f}\left(\mathrm{B}^{(0)}-\Delta_{1}\right)<\mathrm{f}\left(\mathrm{B}^{(0)}\right)<\mathrm{f}\left(\mathrm{B}^{(0)}+\Delta_{1}\right) \\
& \left.\mathrm{B}^{(0)}, \quad \text { if } \mathrm{f}\left(\mathrm{B}^{(0)}\right)<\min \left[\mathrm{f}\left(\mathrm{B}^{(0)}+\Delta_{1}\right), \mathrm{f}^{(0)}-\Delta_{1}\right)\right]
\end{aligned}
$$

Now, instead of perturbing the next variable $\mathrm{x}_{2}$ about the original base $\mathrm{B}^{(0)}$, the temporary position $\mathrm{T}_{1}{ }^{(0)}$ is used. The $\mathrm{T}_{2}{ }^{(0)}$ will be computed as the new temporary position. In general, the gth temporary position $\mathrm{T}_{\mathrm{g}}{ }^{(0)}$, is obtained from $\mathrm{T}_{\mathrm{g}-1}{ }^{(0)}$ by the following equation:

$$
\mathrm{T}_{\mathrm{g}}{ }^{(0)}=\mid \begin{aligned}
& \mathrm{T}_{\mathrm{g}-1}{ }^{(0)}+\Delta_{\mathrm{g}}, \text { if } \mathrm{f}\left(\mathrm{T}_{\mathrm{g}-1}{ }^{(0)}+\Delta_{\mathrm{g}}\right)<\mathrm{f}\left(\mathrm{T}_{\mathrm{g}-1}{ }^{(0)}\right) \\
& \mathrm{T}_{\mathrm{g}-1}{ }^{(0)}-\Delta_{\mathrm{g},} \text {, f } \mathrm{f}\left(\mathrm{T}_{\mathrm{g}-1}{ }^{(0)}-\Delta_{\mathrm{g}}\right)<\mathrm{f}\left(\mathrm{T}_{\mathrm{g}-1}{ }^{(0)}\right)>\mathrm{f}\left(\mathrm{T}_{\mathrm{g}-1}{ }^{(0)}+\Delta_{\mathrm{g}}\right) \\
& \left.\mathrm{T}_{\mathrm{g}-1}{ }^{(0)}, \quad \text { if } \mathrm{f}\left(\mathrm{T}_{\mathrm{g}-1}{ }^{(0)}\right)<\min \left[\mathrm{f}\left(\mathrm{T}_{\mathrm{g}-1}{ }^{(0)}+\Delta_{\mathrm{g}}\right), \mathrm{f} \mathrm{T}_{\mathrm{g}-1}{ }^{(0)}-\Delta_{\mathrm{g}}\right)\right]
\end{aligned}
$$

This equation covers all $\mathrm{g},(0 \leq \mathrm{g} \leq \mathrm{n})$, provided that we use the convention that $\mathrm{T}_{0}{ }^{(0)}=\mathrm{B}^{(0)}$. 
The approach can be continued for other variables. When all the variables have been dealt with, the last temporary point, $\mathrm{T}_{n}{ }^{(0)}$, is denoted as the second base point, $\mathrm{B}^{(1)}\left(\right.$ i.e. $\left.\mathrm{B}^{(1)=} \mathrm{T}_{\mathrm{n}}{ }^{(0)}\right)$. All these moves, which determine the progression from $\mathrm{B}^{(0)}$ to $\mathrm{B}^{(1)}$ suggest a pattern of movement. Next, it can be assumed that the pattern may continue and we start the search for the next temporary position not around $\mathrm{B}^{(1)}$ but at a point $2\left(\mathrm{~B}^{(1)}-\mathrm{B}^{(0)}\right)$ away from $\mathrm{B}^{(0)}$. Therefore, $\mathrm{T}_{0}^{(1)}$ can be found as:

$$
\mathrm{T}_{0}^{(1)}=\mathrm{B}^{(0)}+2\left(\mathrm{~B}^{(1)}-\mathrm{B}^{(0)}\right)=2 \mathrm{~B}^{(1)}-\mathrm{B}^{(0)}
$$

This means that we are progressing from $\mathrm{B}^{(0)}$ to $\mathrm{B}^{(1)}$ to $\mathrm{T}_{0}^{(1)}$.

A local search is now required around $\mathrm{T}_{0}{ }^{(1)}$. The equations for finding $\mathrm{T}_{\mathrm{g}}^{(1)}$ for $\mathrm{g}$ $=1, \ldots, n$ are the same as those for $\mathrm{T}_{\mathrm{g}}{ }^{(0)}$ with superscript 1 instead of zero. If the final temporary position, $\mathrm{T}_{\mathrm{n}}{ }^{(1)}$, improves the value of the objective function at $\mathrm{B}^{(1)}$, this becomes the new base point.

$$
\mathrm{B}^{(2)}=\mathrm{T}_{\mathrm{n}}^{(1)} \text { if } \mathrm{f}\left(\mathrm{T}_{\mathrm{n}}^{(1)}\right)<\mathrm{f}\left(\mathrm{B}^{(1)}\right)
$$

If this condition is met, we can take a further "double step" away from $\mathrm{B}^{(1)}$ and go beyond $\mathrm{B}^{(2)}$. Thus, we can find the temporary position $\mathrm{T}_{0}^{(2)}$ and carry out new exploratory searches around it:

$$
\mathrm{T}_{0}^{(2)}=2 \mathrm{~B}^{(2)}-\mathrm{B}^{(1)}
$$

If this move turns out to be a false move, we have to go back to the previous base point. After continuing this procedure, if there is no improvement, the step length should be changed to a smaller step length than the initial step lengths. The whole procedure should be repeated until the required accuracy is obtained.

An algorithm was developed to formalize the use of the direct search method and it was integrated as a part of the methodological framework shown in Figure 1. Alternatively, direct search algorithms included in the optimization toolbox for use with MATLAB could be considered (Math Works Inc. 2000). 


\section{Case Study}

The methodology was applied to a major multimodal travel corridor in Ottawa (Canada) for the P.M. peak period. In Ottawa, three major travel corridors connect satellite urban centers with the central business district (CBD) (Figure 3). These corridors feature high volume routes for automobile travel and bus rapid transit service based on the transitway technology (Regional Municipality of OttawaCarleton 1997, Nisar and Khan 1992). The eastern corridor was selected as the case study area. The travel demand, infrastructure, and other factors correspond to year 2011. A major highway (i.e., the Queensway), which is a part of the corridor, can be converted into an electronic toll route.

Given Ottawa's multinucleated land-use pattern and the high quality transportation infrastructure already in place, the objective of the research study was to determine the best values of highway tolls, parking charges in the $C B D$, and public transit fare in order to minimize a specified objective function.

To be helpful in planning demand management strategies, the future year 2011 was used. Since the intent was to make highway tolls a part of demand management measures and recognizing the fact that it takes time to implement this measure, the 2011 horizon was a logical choice. Another reason was the completion of the public transit infrastructure.

The following objective functions were investigated:

- Minimum in-vehicle time/pass-km. This objective function reflects the policy objective of enhancing mobility by improving average travel speed.

- Minimum fuel consumption/minimum GHG emissions. Given that the GHG emissions are a direct function of fuel consumption, no separate runs were required.

- Minimum air quality pollutants.

A specific combination of a toll charge, parking charge, and transit fare defined as a base point in the direct search method serves as a scenario for demand management. These are the important price variables that can potentially be influenced by urban transportation policy-makers. Prices are expressed in 1999 dollars. The breadth of scenarios tested can be appreciated by examining the range of values of the inputs. For example, average parking charge varies from $\$ 2.10$ to $\$ 7.70$ and toll varies from 0 cents to 14 cents $/ \mathrm{km}$. A realistic range of bus fares is used, keeping in 
Journal of Public Transportation, Vol. 6, No. 2, 2003

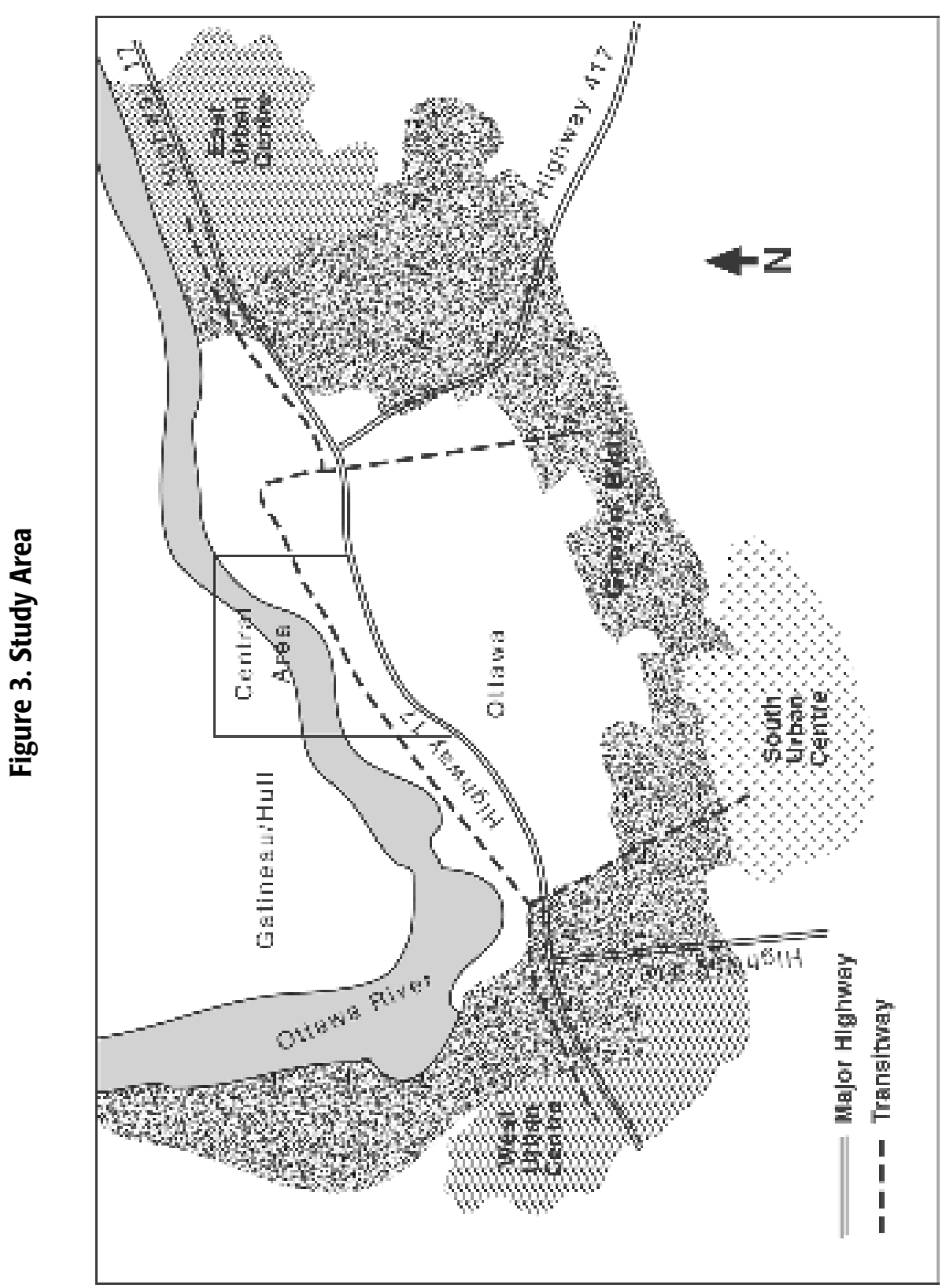


mind the very heavy government subsidy implications for free transit or offering service at extremely low fare levels.

Travel demand for 2011 was estimated by using the EMME/2 framework and associated models. The focus is on three price types of variables, given that these can be influenced by transportation authorities. All other variables in the demand model are held constant. For the initial scenario, minimum but realistic values of control variables (i.e., parking charges, bus fare, and tolls) were used. Parking charges reflect a weighted average of all types of long-term as well as short-term parking fees paid in central Ottawa. Likewise, bus fare is the weighted average of all types of bus pass and cash fares. Since in the base case, there are no tolls on the highway, toll charge is set at zero. In the application of the optimization method, reasonably refined step lengths for changing the values of variables were used.

The order of presentation of control variable values reflects the operational aspects of the methodology. The sequence of their presentation can be appreciated by looking at the parking charge variable. It starts with $\$ 2.10$ (lowest value) and gradually increases to the maximum value of $\$ 7.70$ (in 1999 dollars). From there on, it takes values as required in conjunction with other control variable values. The pattern of other control variables is driven by the values of the parking charge variable.

Owing to space limitation, air quality pollutants are not covered in this article. A brief introduction to calculation of GHG emissions is provided here. As a result of fuel consumption by internal combustion engines, in addition to other emissions, the following notable $\mathrm{GHG}$ emissions are produced: carbon dioxide $\left(\mathrm{CO}_{2}\right)$, methane $\left(\mathrm{CH}_{4}\right)$, and nitrogen oxide $\left(\mathrm{N}_{2} \mathrm{O}\right)$. The magnitude of these emissions per liter of fuel varies by type of fuel, engine, and emission control technologies. To find the $\mathrm{CO}_{2}$ equivalent of these gases, equivalency factors are used which reflect their relative long-term greenhouse effect. The equivalency factors are: 1 for $\mathrm{CO}_{2 ;} 21, \mathrm{CH}_{4 ;}$ and 310, $\mathrm{N}_{2} \mathrm{O}$ (Khan 1999). On the basis of fuel consumed/pass-km, GHG emissions/liter of fuel, and the $\mathrm{CO}_{2}$ equivalency factors, $\mathrm{GHG}$ emissions were computed on a pass $-\mathrm{km}$ basis. 


\section{Results}

Selected inputs and outputs for different applications of the optimization methodology noted earlier are presented as 23 scenarios (Tables 1 and 2).

Table 1.

Modal Split, In-Vehicle Travel Time: 2011 PM Peak Period

\begin{tabular}{|c|c|c|c|c|c|c|c|}
\hline \multirow[t]{2}{*}{ Scenario } & \multirow{2}{*}{$\begin{array}{l}\text { Parking } \\
\text { Charge } \\
\text { (\$/day) }\end{array}$} & \multirow{2}{*}{$\begin{array}{c}\text { Bus Fare } \\
\text { (\$/trip) }\end{array}$} & \multirow{2}{*}{$\begin{array}{c}\text { Toll } \\
\text { (Cents/ } \\
\text { Km) }\end{array}$} & \multicolumn{3}{|c|}{ Modal Split (\%) } & \multirow{2}{*}{$\begin{array}{l}\text { In-vehicle } \\
\text { Travel Time } \\
\text { Sec/pass-km) }\end{array}$} \\
\hline & & & & Bus & Car & Carpool & \\
\hline 1 & 2.10 & 1.20 & 0 & 34.5 & 51.0 & 14.5 & 120.7 \\
\hline 2 & 2.80 & 1.20 & 0 & 37.0 & 48.5 & 14.5 & 120.2 \\
\hline 3 & 2.80 & 1.20 & 7 & 37.5 & 48.0 & 14.5 & 119.0 \\
\hline 4 & 2.80 & 1.60 & 7 & 36.1 & 49.1 & 14.8 & 119.6 \\
\hline 5 & 3.50 & 1.20 & 14 & 40.4 & 45.1 & 14.5 & 118.7 \\
\hline 6 & 4.20 & 1.20 & 14 & 42.8 & 42.8 & 14.4 & 118.5 \\
\hline 7 & 4.20 & 1.20 & 7 & 42.4 & 43.2 & 14.4 & 118.3 \\
\hline 8 & 4.20 & 1.60 & 7 & 41.0 & 44.2 & 14.8 & 118.6 \\
\hline 9 & 4.90 & 1.20 & 0 & 44.3 & 41.5 & 14.2 & 118.6 \\
\hline 10 & 4.90 & 1.20 & 7 & 44.6 & 41.2 & 14.2 & 118.1 \\
\hline 11 & 5.60 & 1.20 & 7 & 46.7 & 39.3 & 14.0 & 117.8 \\
\hline 12 & 5.60 & 1.60 & 7 & 45.5 & 40.1 & 14.4 & 118.2 \\
\hline 13 & 7.00 & 1.20 & 7 & 50.2 & 36.4 & 13.4 & 118.0 \\
\hline 14 & 7.70 & 1.20 & 7 & 51.5 & 35.3 & 13.2 & 118.3 \\
\hline 15 & 6.30 & 1.20 & 7 & 48.5 & 37.8 & 13.7 & 118.0 \\
\hline 16 & 7.00 & 1.60 & 7 & 49.2 & 37.0 & 13.8 & 118.1 \\
\hline 17 & 7.00 & 1.20 & 14 & 50.4 & 36.2 & 13.4 & 118.7 \\
\hline 18 & 5.80 & 1.20 & 7 & 47.1 & 39.0 & 13.9 & 117.9 \\
\hline 19 & 5.60 & 1.20 & 7 & 46.3 & 39.7 & 14.0 & 117.9 \\
\hline 20 & 5.60 & 1.20 & 8 & 46.7 & 39.3 & 14.0 & 118.0 \\
\hline 21 & 5.60 & 1.20 & 6 & 46.6 & 39.4 & 14.0 & 117.9 \\
\hline 22 & 5.60 & 1.30 & 7 & 46.4 & 39.5 & 14.1 & 118.1 \\
\hline 23 & 7.70 & 1.20 & 14 & 51.7 & 35.2 & 13.1 & 119.0 \\
\hline
\end{tabular}

Notes: (1) All dollars are in 1999 constant \$.

(2) Very little variation in in-vehicle times reflects the absence of severe congestion and the performance of bus rapid transit vis-à-vis automobile travel facilities. 
Table 2.

Modal Split, Fuel Consumption, and GHG Gas Emissions:

2011 PM Peak Period

\begin{tabular}{|c|c|c|c|c|c|c|c|c|}
\hline \multirow[t]{2}{*}{ Scenario } & \multirow{2}{*}{$\begin{array}{l}\text { Parking } \\
\text { Charge } \\
\text { (\$/day) }\end{array}$} & \multirow{2}{*}{$\begin{array}{c}\text { Bus } \\
\text { Fare } \\
\text { (\$/trip) }\end{array}$} & \multirow{2}{*}{$\begin{array}{c}\text { Toll } \\
\text { (Cents/ } \\
\text { Km) }\end{array}$} & \multicolumn{3}{|c|}{ Modal Split (\%) } & \multirow{2}{*}{$\begin{array}{c}\text { Fuel } \\
\text { Consumption } \\
\text { (ml/pass-km) }\end{array}$} & \multirow{2}{*}{$\begin{array}{c}\text { GHG } \\
\text { Emissions } \\
(\mathrm{gm} / \text { pass-km) }\end{array}$} \\
\hline & & & & Bus & Car & Carpool & & \\
\hline 1 & 2.10 & 1.20 & 0 & 34.5 & 51.0 & 14.5 & 60.5 & 143.5 \\
\hline 2 & 2.80 & 1.20 & 0 & 37.0 & 48.5 & 14.5 & 56.5 & 134.0 \\
\hline 3 & 2.80 & 1.20 & 7 & 37.5 & 48.0 & 14.5 & 55.7 & 132.2 \\
\hline 4 & 2.80 & 1.60 & 7 & 36.1 & 49.1 & 14.8 & 57.4 & 136.1 \\
\hline 5 & 3.50 & 1.20 & 14 & 40.4 & 45.1 & 14.5 & 51.3 & 121.8 \\
\hline 6 & 4.20 & 1.20 & 14 & 42.8 & 42.8 & 14.4 & 47.9 & 113.7 \\
\hline 7 & 4.20 & 1.20 & 7 & 42.4 & 43.2 & 14.4 & 48.4 & 114.9 \\
\hline 8 & 4.20 & 1.60 & 7 & 41.0 & 44.2 & 14.8 & 49.8 & 118.2 \\
\hline 9 & 4.90 & 1.20 & 0 & 44.3 & 41.5 & 14.2 & 45.6 & 108.4 \\
\hline 10 & 4.90 & 1.20 & 7 & 44.6 & 41.2 & 14.2 & 45.2 & 107.4 \\
\hline 11 & 5.60 & 1.20 & 7 & 46.7 & 39.3 & 14.0 & 42.3 & 100.6 \\
\hline 12 & 5.60 & 1.60 & 7 & 45.5 & 40.1 & 14.4 & 43.5 & 103.3 \\
\hline 13 & 7.00 & 1.20 & 7 & 50.2 & 36.4 & 13.4 & 38.0 & 90.3 \\
\hline 14 & 7.70 & 1.20 & 7 & 51.5 & 35.3 & 13.2 & 36.4 & 86.6 \\
\hline 15 & 6.30 & 1.20 & 7 & 48.5 & 37.8 & 13.7 & 40.0 & 95.1 \\
\hline 16 & 7.00 & 1.60 & 7 & 49.2 & 37.0 & 13.8 & 38.8 & 92.3 \\
\hline 17 & 7.00 & 1.20 & 14 & 50.4 & 36.2 & 13.4 & 38.0 & 90.4 \\
\hline 18 & 5.80 & 1.20 & 7 & 47.1 & 39.0 & 13.9 & 41.8 & 99.4 \\
\hline 19 & 5.60 & 1.20 & 7 & 46.3 & 39.7 & 14.0 & 42.8 & 101.8 \\
\hline 20 & 5.60 & 1.20 & 8 & 46.7 & 39.3 & 14.0 & 42.3 & 100.5 \\
\hline 21 & 5.60 & 1.20 & 6 & 46.6 & 39.4 & 14.0 & 42.4 & 100.8 \\
\hline 22 & 5.60 & 1.30 & 7 & 46.4 & 39.5 & 14.1 & 42.6 & 101.3 \\
\hline 23 & 7.70 & 1.20 & 14 & 51.7 & 35.2 & 13.1 & 36.5 & 87.0 \\
\hline
\end{tabular}

Most impacts (i.e., outputs) show much variation. For example, modal share for bus ranges from 34.5 percent to 51.7 percent. Fuel consumption (in milliliters/ pass-km) varies from 36.4 to $60.5 \mathrm{ml} /$ pass- $\mathrm{km}$. On the other hand, the in-vehicle travel time ( $\mathrm{sec} /$ pass- $\mathrm{km}$ ) shows very small variation in spite of a very high diversion from automobile to bus. These figures suggest that there is an absence of severe congestion in the case study corridor. Also, the bus rapid transit is competi- 
tive with high quality automobile travel facilities in terms of in-vehicle travel time. Should this methodology be applied to a highly congested urban area, the in-vehicle travel time may show a different pattern.

Although door-to-door travel time is not reported in this article due to space limitation, a brief comment is offered for the benefit of the interested reader. While the in-vehicle travel times for bus and automobile are comparable, as expected, total (door-to-door) travel time for bus is higher than for the automobile. The out-of-vehicle time components are responsible for this situation.

In relative terms, Scenario 11 is the best for minimizing in-vehicle travel time/pass$\mathrm{km}$. However, as compared to this scenario, Scenario 14 would result in 14 percent saving in fuel consumption (on a m.litre/pass-km basis) and 13.9 percent reduction in GHG emissions (in gm/pass-km). On the other hand, an increase of about 0.4 percent in in-vehicle travel time (sec/pass-km) occurs (Tables 1 and 2 ).

As shown in Table 2, Scenario 14 appeared to be the choice as a starting point for further search on control variables that maximize bus ridership and minimize fuel consumption and $\mathrm{GHG}$ emissions on a per pass-km basis. Based on selected ranges of values of the variables and step lengths, the direct search procedure was used to develop new scenarios. Scenario 23 was created. Although it shows a marginal increase in bus modal split (a $0.2 \%$ gain), the fuel consumption and GHG emissions increase. The reason is that, as compared to Scenario 14, doubling the toll charge in Scenario 23 shifts car traffic from freeway to parallel arterials and results in congested operations. Therefore, Scenario 14 is accepted as the optimal demand management scenario for public transit patronage, fuel consumption and GHG emissions. This scenario represents highly favorable conditions for public transit and yet there would not be hardship for users of other modes. It is also the optimal scenario for minimizing air quality pollutants.

The results shown in Tables 1 and 2 suggest that the demand management instruments used in this research (i.e., bus fare, parking charge, and highway tolls) have a high effect on P.M. peak period bus modal split (34.5\% under Scenario 1 to $51.7 \%$ under scenario 23). Also, there are significant differences between scenarios in terms of fuel and emissions. Furthermore, it is logical to see that the best values of variables for minimizing fuel consumption and GHG emissions occur when public transit modal split is high. 
As compared to scenario 1 (based on minimum values of control variables), Scenario 14 results in 39.8 percent fuel savings (m.litre/pass-km) and 39.6 percent reduction in $\mathrm{GHG}$ emissions ( $\mathrm{g} /$ pass-km).

Thus, in this case study, on the basis of in-vehicle travel time, fuel consumption, GHG emissions, and air quality pollutants as objective functions, scenario 14 can be accepted as the best.

\section{Implementation Issues}

Urban area policy-makers have to agree on policy objective (or objectives) to be achieved. In most Canadian urban regions, favoring public transit over private automobile use for peak travel in high-density traffic areas is a well-accepted principle. Also, a high priority is being accorded to minimizing fuel consumption and emissions. An objective function favorable to energy, environment, and therefore to public transit is realistic. However, it would be beneficial for planners to see the results of minimizing in-vehicle travel time and to compare these with the public transit priority policy. In general, following the identification of the best scenarios that correspond to various objective functions, multiobjective evaluation methods can be used for the selection of the most preferred scenario.

For practical implementation of demand management instruments, it is necessary to define one set of optimal values of variables for application throughout the urban region. This can be achieved by simulating overall urban level travel and the identification of the optimal scenario. On the other hand, if major corridors are studied independently, their results can be compared and a common set of answers obtained for the various corridors can be used.

Another implementation issue is the transit authority option for a fare level that is different than the "optimal" fare. In such a case, the weighted average fare to be charged can be held fixed and values of other variables can be found from the optimization process.

It is logical to question the mechanism for implementing parking charges when the output from the optimization methodology is a "weighted average" parking charge. The answer to this question is that the proportion of each type of parking (i.e., long-term contracts and short-term parking charges) has to be estimated and then an attempt can be made to influence parking charges of each type (e.g., through special taxes). 


\section{Conclusions}

Conceptual and methodological contributions are described in this article. These include (a) the concept of the optimal use of a multimodal corridor and the development of an optimization methodology to accomplish this objective, and (b) methodological capability to find the values of the demand management variables for the optimal use of travel corridors in response to a policy objective.

The results of the corridor travel optimization case study are logical and provide insight into the role of demand management instruments. It is clear that there is a role for highway tolls in conjunction with other demand management variables.

Highly significant gains in transit modal share and reduction in fuel consumption and emissions can be achieved as a result of implementing the optimal values of demand management variables.

For the case study corridor, there is a very small difference between the lowest invehicle time achievable (Scenario 11) and its value under a scenario highly favorable to public transit, energy efficiency and GHG emission reduction. This implies that in a multimodal travel corridor, bus rapid transit can compete with automobile in attracting choice riders and offering slightly improved in-vehicle travel times. Additionally, bus rapid transit can assist in reducing corridor-level fuel consumption and emissions.

\section{Acknowledgments}

This research was funded by the Natural Science and Engineering Research Council of Canada (NSERC). The views expressed are those of the authors. 


\section{References}

INRO Consulting Limited. 1999. EMME/2 Software Package. Montreal.

Khan, A. M. 1999. Issues in the use of EMME/2 as a platform for the estimation of greenhouses. Journal of the University of Shanghai for Science and Technology 21 (3).

Math Works Inc. 2000. The optimization toolbox 2.0 for use with MATLAB. Natick, MA.

Nicholoson, T. A. J. 1971. Optimization in the industry, optimization techniques 1. London: Longman Group Limited.

Nisar, M., and A. M. Khan. 1992. Transitway: An innovation in public transportation. ITE Journal 62 (7).

Radin, R. L. 1998. Optimization in operations research. Upper Saddle River, NJ: Prentice-Hall, Inc.

Regional Municipality of Ottawa-Carleton. 1997. Transportation master plan: Mass transit. Prepared by Dillion Consulting Limited, Paper \#19-46.

Smart Urban Transport. March 2002. New York forum explores FAIR lanes. (http:/ /www.smarturbantransport.com).

Zargari, S. A., and A. M. Khan. 1998. A simulation model of the bus transitway (TRANSIM). Journal of Advanced Transportation 32 (2).

Zargari, S. A., and A. M. Khan. 2003. Fuel consumption model for bus rapid transit. Journal of Advanced Transportation 37 (2) (accepted for publication).

\section{About the Authors}

Shahriar A. ZarGari (Zargari@iust.ac.ir) received his bachelor's and master's degrees in civil engineering from the Iran University of Science and Technology, Tehran (Iran) and his Ph.D. degree in civil engineering (transportation) from Carleton University, Ottawa, Canada. At present he is an assistant professor at the Iran University of Science and Technology, Tehran.

Ata M. Khan (ata_khan@carleton.ca) received his B.Eng. and M.Eng. in civil engineering from the American University of Beirut and his doctorate from the Uni- 
Journal of Public Transportation, Vol. 6, No. 2, 2003

versity of Waterloo (Canada) in civil engineering (transportation). He is a professor in the Department of Civil and Environmental Engineering at Carleton University, Ottawa. 